Birch, C J, et al, fournal of Medical Virology, 1977, 1, 69.

Middleton, P J, et al, fournal of Clinical Pathology, 1976, 29, 191.

Nastasi, M C, Pringle, R C, and Gust, I D, Australian fournal of Medical Technology, 1972, 3, 111

1" Yolken, R H, et al, Lancet, 1977, 2, 263

British Medical fournal, 1975, 3,555.

12 Ryder, R W, et al, Lancet, 1976, 1, 659.

1:3 Schoub, B D, et al, Fournal of Hygiene, 1977, 78, 377

4 De Groote, G, et al, Lancet, 1977, 1, 1263

${ }^{5}$ Madeley, C R, et al, fournal of Hygiene, 1977, 78, 261.

\section{Finger clubbing and hypertrophic pulmonary osteoarthropathy}

Every final-year medical student knows that clubbing of the fingers can be caused by intrathoracic sepsis, carcinoma of the lung, bacterial endocarditis, and cyanotic congenital heart disease; and honours candidates may add carcinoma of the thymus or thyroid, leiomyoma of the oesophagus, Hodgkin's disease of the thorax, disseminated chronic myeloid leukaemia, pleural mesothelioma or fibroma, achalasia or peptic ulceration of the oesophagus, cirrhosis of the liver, and ulcerative colitis. The small-print enthusiast can add cystic fibrosis, ${ }^{1}$ pulmonary metastases ${ }^{2}$ from numerous sources including hypernephroma and melanoma, ${ }^{3}$ nasopharyngeal carcinoma, ${ }^{4}$ as a rarity in repeated pregnancies, and reversibly in purgative abuse. ${ }^{5}$ This formidable list does not deny the diagnostic value of clubbing, particularly as suggestive of carcinoma of the bronchus, bacterial endocarditis, and intrathoracic suppuration, for these will account for most cases in everyday clinical practice.

Hypertrophic pulmonary osteoarthropathy may complicate simple clubbing and present with periostitis with new bone formation in the limbs, possibly synovial hypertrophy with joint effusions, and abnormal sweating of the palms and soles. Some authorities have suggested that clubbing is not essential for the diagnosis of hypertrophic pulmonary osteoarthropathy, ${ }^{6}$ and the subtleties of early clubbing often evoke semantic debate at the bedside. The clinical hallmark of osteoarthropathy is painful periarticular or joint swellings over the wrists, knees, ankles, or elbows. The swelling and tenderness may be associated with morning stiffness and may mimic rheumatoid arthritis; the raised sedimentation rate may appear to confirm this suspicion, and it may be further reinforced by symptomatic relief from aspirin, indomethacin, or steroids, though the bony changes do not resolve. The typical radiological appearances of the periostitis of the long bones is usually diagnostic, but in unusual cases where joint features predominate the synovial fluid has been found to be "non-inflammatory" with a low leucocyte count and few neutrophils, serving to differentiate the condition from rheumatoid arthritis.

Recent advances with radionuclide ${ }^{99 \mathrm{~m}} \mathrm{Tc}$ phosphate complexes have helped to solve diagnostic confusion between hypertrophic osteoarthropathy and bone metastases in patients with carcinoma of the bronchus and may also allow the condition to be diagnosed with some certainty before the appearance of the characteristic radiological changes. ${ }^{7}$ Highquality radionuclide images show pericortical deposition in hypertrophic osteoarthropathy, in contrast to a central increase in concentration of the radiopharmaceutical in bony metastases.

Though the mechanism of clubbing and hypertrophic pulmonary osteoarthropathy remains unknown, at least three theories have been advanced to explain the phenomenon. The neuronal theory proposes that afferent impulses travel by the vagus or intercostal nerves from the causative pulmonary focus, but the efferent pathway from the nervous system remains a mystery. Regression of the arthropathy after cervical or superior mediastinal vagotomy ${ }^{89}$ is advanced as evidence for this thesis. The hormonal theory, originating with Maric in 1890, currently advocates the production of a circulating agent capable of producing the clubbing and osteoarthropathy which is normally inactivated by passage through the pulmonary circulation. This attractive hypothesis unfortunately has little experimental support: changes in neither oestrogen ${ }^{10}$ nor human growth hormone ${ }^{11}$ are related to the syndrome. ${ }^{12}$ An extension of the hormonal theory invokes arteriovenous shunting across the lung, as in cyanotic congenital heart disease, which allows an unknown hormone-like substance to escape into the systemic circulation, but again this mysterious material has never been isolated. Studies using krypton clearance to measure blood flow have confirmed the earlier impression, based upon venous occlusion plethysmography, that the blood flow to the clubbed fingers is increased, ${ }^{13}$ but this has been questioned in hypertrophic pulmonary osteoarthropathy..$^{14} \mathrm{~A}$ recent postmortem study ${ }^{15}$ also failed to find any consistent increase in the vascularity of the tissues of the nail bed in clubbed fingers, and there was also little difference in the mast cell counts in clubbed and control fingers.

The pain of hypertrophic pulmonary osteoarthropathy has been relieved by vagotomy, hypophysectomy, intercostal nerve section, exploratory thoracotomy, or by radiotherapy to the causative lung lesion. ${ }^{16}$ The vascularity of the joint lesions, as assessed by thermography, can also be reduced by combined alpha- and beta-adrenergic blockade. ${ }^{17}$ It seems odd that despite this apparent plethora of clues the physiopathological mechanism underlying clubbing and hypertrophic osteoarthropathy remains an enigma.

${ }^{1}$ Matthay, M A, et al, Thorax, 1976, 31, 572.

2 Firooznia, H, et al, Radiology, 1975, 115, 269.

${ }^{3}$ Sonoda, T, and Krauss, S, Fournal of the Tennessee Medical Association, $1975,68,716$.

${ }^{4}$ Chio, K, Medical Fournal of Malaysia, 1975, 30, 127.

${ }^{5}$ Silk, D B, Gibson, J A, and Murray, C R, Gastroenterology, 1975, 68, 790.

'S Schumacher, H R, Arthritis and Rheumatism, 1976, 19, 629.

Rosenthall, L, and Kirsh, J, Radiology, 1976, 120, 359.

Flavell, G, Lancet, 1956, 1, 260.

${ }^{9}$ Yacoub, M H, British Fournal of Diseases of the Chest, 1965, 59, 28.

10 Ginsberg, J, and Brown, J B, Lancet, 1961, 2, 1274.

1 Steiner, H, Dahlbäck, O, and Waldenström, J, Lancet, 1968, 1, 783.

12 Riyami, A M, and Anderson, E G, British fournal of Diseases of the Chest, $1974,68,193$.

${ }^{13}$ Racoceanu, S N, et al, Annals of Internal Medicine, 1971, 75, 933.

14 Ginsberg, J, Quarterly fournal of Medicine, 1958, 27, 335.

${ }_{15}$ Marshall, R, American Review of Respiratory Diseases, 1976, 113, 395.

${ }^{16}$ Steinfeld, A D, and Munzenrider, J E, Radiology, 1974, 113, 709.

1: Reardon, G, Collins, A J, and Bacon, P A, Postgraduate Medical fournal, 1976, 52, 170 .

\section{Obdurate politics}

When Mrs Barbara Castle introduced the DHSS consultative document on priorities ${ }^{1}$ in March 1976 she undertook to modify the plan in the light of comments from health authorities, professional and staff associations, community health councils, and voluntary bodies. Her strategy-at a time when the nation's economic outlook was especially bleakwas to maintain a $1.8 \%$ rise in current NHS expenditure by cutting back the capital building programme. Her choice of priorities was equally clear: more resources were to be given 